\title{
Smart Border for Disease Control
}

\author{
Pakamas Pairot and Supaporn Kiattisin* \\ Information Technology Management, Faculty of Engineering, Mahidol University \\ Salaya, Phuttamonthon, NakhonPathom, Thailand \\ E-Mail:pakamas.pai@student.mahidol.ac.th; supaporn.kit@mahidol.ac.th \\ ${ }^{*}$ Corresponding Author
}

Received 16 February 2020; Accepted 07 May 2020;

Publication 17 August 2020

\begin{abstract}
Border crossing poses various risks, such as national security risks, risk of terrorism, and human trafficking, as well as the risk of an epidemic. In the process of disease control, Thailand has a system and mechanism of control in accordance with the standards of the World Health Organization and is recognized for the precision and tightness of the process. However, the screening and control process at land and marine border checkpoints still face the risks associated with cross border disease control due to the lack of preliminary information from passengers before crossing the border similar to those at an air-border crossing. It was found that the agencies involved in the land crossborder process would only become aware of passenger information when the passenger arrived at the crossing point. Initial screening and preparation procedures for coping with the risks were not timely, including the various resources at the border checkpoints such as screening tools, personnel, and screening sites. This paper aims to develop a cross-border management model that can help screen for diseases and support national security through digital technology. Therefore, the hypothesis has been proposed through the form of electronic border checkpoints for prevention, control, and tracking of transnational epidemics by screening all cross-border travelers. The existing system will be studied. The principles of collaborative border management $(\mathrm{CBM})$ are the basis for the design, linkage, and integration between relevant departments. Further, simulation is a proof of our concept. The results show
\end{abstract}

Journal of Mobile Multimedia, Vol. 16_1-2, 131-160.

doi: 10.13052/jmm1550-4646.16127

(C) 2020 River Publishers 
that data linkage and coordination between organizations build confidence and safety, reduces the risk of infection to people traveling across border agencies, and is in accordance with the National Digital Policy.

Keywords: International border, disease control, smart border, electronic border, collaborative border management.

\section{Introduction}

Cross-border activity is important in promoting economic activity. At the same time, it is considered a weak point for national security. The purpose for land crossings is different, whether it is for work or an educational trip. However, cross-border management needs to be linked to both international and local organizations $[1,2,3,4]$. The positive results arising from crossing the border are the economic benefits associated with the business of trade. Tourists, as a part of the tourism supply chain, are one of the main revenue sources in Thailand today. However, cross-border activity is also a risk for nations, such as the risk of terrorism or human trafficking [5, 6], as well as the risk of multinational diseases and national threats $[7,8,9]$. For this reason, a quick but safe process is the goal and the key to cross-border activities in Thailand, a country where the main revenue comes from tourist activities and cross-border activities. In 2019, it was found that travel income was $12 \%$ of Thailand's GDP. The screening process at the border checkpoint also affected the satisfaction of travelers [10]. Revenue from international trade was also one of the main factors resulting in income and the creation of domestic jobs. In Thailand, the revenue from the import and export of goods in 2019 was $16 \%$ and $18 \%$ of the GDP due to the importance of trade and tourism to the domestic economy. As such, ensuring future confidence and security in the country's cross-border processes is paramount and it will ensure the satisfaction of the traveler as well.

In Thailand, an automated system is used to facilitate immigration and reduce travel time, including the autoGate of biometric technology in order to verify identity, this technology being operated by the immigration police personnel. The systems are installed at the international airports of Thailand, including the Suvarnabhumi Airport and the Don Mueang Airport. Airlines must complete the passenger registration process with the passenger information system (Advance Passenger Information System, APIS) [11, 12] and system monitoring and screening of passengers in advance (Advance Passenger Processing System, APPS), both of which are useful in the preliminary 
identification of travelers. It helps to filter out basic information about crime and traveler's activity, and prepare the airport facilities to accommodate passengers travelling in an aircraft and upon arrival at the airport. The travelers should be able to present themselves for immigration chek and hence support the various other corresponding aspects. Identifying different passengers or other aspects of tracking people in the city is easier and safer. The activities in this section allow the tracing and identification of people, which can lead to the control and prevention of multinational crimes, human trafficking, and offender tracking.

In addition to the aerial frontier, land and marine border checkpoints are also at risk for preventing and controlling the multinational disease. At the time of risk, land and marine checkpoints have to be more careful than air frontiers due to the lack of identification of preliminary passenger information before crossing the checkpoint. It is found that the agencies involved in the cross-border process will only know the passenger's information when they arrive at the border point. One of the benefits of the preliminary screening at land border crossings is that it does not depend on the individual circumstances of each border checkpoint, and thus allows the preparation for various risks irrespective of screening sites. Furthermore, it is a useful tool in filtering travelers who may be in the at-risk group prior to their arrival at the border-crossing. The preparation of the border screening process requires more time, and in places where the number of personnel is limited this may burden the number of personnel employed for other tasks. This will reflect in an increased time for the screening process, which can result in an increased risk of infection for people traveling within enclosed spaces or those who may have had contact with a carrier in the spread of germs. Should a panic emerge, the dissemination of false information may lead to a more severe situation than before.

This paper aims to propose a model for screening and tracking of travelers through a mechanical linkage between the relevant authorities to allow them to be able to control and track travelers across land border crossings, as even standardized monitoring processes do not allow real time information sharing between tracking agencies [13], ad-hoc workflow, and business silo. Therefore, the researchers are interested in developing a cross-border management approach that will help prevent the spread of disease. This study proposes the hypothesis of electronic border protection to control epidemics by tracking all cross-border travelers. The existing system is studied and analyzed. Simulation is used as a system performance evaluation of the As-Is and To-Be process in accordance with the proposed model. The results show 
that the proposed model is supportive of the activity of border control and ensures security. In addition, the policy recommendations are consistent with the National Digital Policy.

\section{Literature Review and Related Research}

\subsection{Cross-border Management}

The border is an area separated by political boundaries. It consists of geographical areas adjacent to other countries [14]. Border control is for monitoring or regulating the border of a country. It includes the control and movement of people, animals, and goods into and out of the country. To monitor the border, the World Bank and the European Union $[3,15,16]$ have recommended that border checkpoints should consist of the following:

\section{Border surveillance and border check}

The border surveillance and border checks aim to monitor the movement of people across border whether they are authorized to enter the state or not. Monitoring includes the check of transportation means. In Thailand, the Immigration Police are responsible for the role of cross-border checks.

\section{Customs Agencies}

Customs agencies play an important role in the control of goods across a border. The collection of duties and other revenues also falls under the authorization of the customs agencies.

\section{Inspection of plant and plant products}

The inspection of plants and plant products also plays an important role in the cross-border checks in terms of control and monitoring of harmful organisms. The import and transit of plants and plant products need to be closely coordinated with customs control agencies.

\section{Inspection of live animals and products of animal origin}

The outbreak of animal and food-borne illnesses needs to be prevented. The inspection of live animals and food stuffs, as well as other products of animal origin, plays a crucial role in the prevention of such illnesses. The customs agency also works closely with the inspection of live animals and products of animal origin. 


\section{Human health inspection}

Health inspection is needed as a primary result of outbreak or illness. In Thailand, the Ministry of Health and the Department of Disease Control (DDC) is responsible for human health inspection.

\subsection{Theories of Cross-Border Management}

As efficacy and efficiency in the cross-border control requires collaboration from all related authorities, a collaborative border management (CBM) system is required. The cross-border management aims to facilitate the movement of cross-border trade and people with efficacy and accuracy. In general, a cross-border management model can be divided into four types: Single Agency, Multi-Agency, Integrated Border Management, and One Stop Border Post [14]. There are many theories for cross-border management [17]. The definitions of cross-border management in collaboration of control authorities can be defined in similar ways. World Customs Organization (WCO) has defined a cross-border management as "a border management methodology that involves government agencies working together to achieve common objectives in response, to challenge the border management in the same direction by managing the border together as a way of managing operations in order to create efficiency and effectiveness in the steps and methods, and the operation of all agencies relating to border security and law enforcement to passengers, goods and moving through international border areas. The purpose of the border management system is to facilitate convenience, trade, and travel of passengers without any security at the border." The European Union has defined cross-border management in the same way as the WCO and the OSCE. However, cross-border management under the definition of Tom Doyle [18] has a more specific focus on the use of information technology and data sharing for the collaborative work. Hence, this paper has adopted a CBM theory as a guideline for model development.

\subsubsection{Collaborative border management}

CBM[18] is the concept of cross-border trade and facilities among related organizations. This concept is to make sure that all parties relevant in the border-crossing process can benefit from the common aims of resource sharing and coordination. In this concept, the work and activities performed 
are like a "virtual border." The operation, as well as the outcome of the activities, can be linked and shared, the supply chain of goods and people can be assessed for admissibility and clearance in advance of arriving at the physical border.

The key components of the CBM consist of policy, process, people, technology infrastructure, and facilities. Information sharing is one key for the success of the CBM. The level of cross-border management is in three stages: International level, Interagency level, and Intra service level.

\subsection{Systems Related to the Border Crossing}

The process of border crossing can be defined as being in three stages: prearrival, entry, and after entry. The prearrival process includes the visa and preclearance system, which can allow the benefits of time saving, eliminating the duplication of check-in traveler data, and making effective resource allocation. The entry processes are focused on the identification and verification of travelers, while the after-entry process focuses on the tracking of travelers during stays by compiling in-country applications and law enforcement actions. The European Union is a model of cross border process development on cross-border standards. The free movement policy is set for people to travel freely across the union and the free movement of goods on crossborder trade. In order to implement this policy, it requires the cross-border standards and currency to be transformed, and the policy must be applied to the whole of the European Union $[19,20]$. The smart border concept is compiled over the union. In the borders of the United States and Mexico, it has recognized the busiest cross-border checkpoint with thousands of people and goods along the border. Smuggling and crimes also form the majority of cross-border risk. The screening process at a border checkpoint is extremely elaborate. Video camera face recognition and other advanced technologies are adopted for the prevention of cross-border risk. After the project was implemented, the flow of people and vehicles is recorded with correctness and safety. According to the system, Australia has adopted the concept of e-border in its Universal Visa System. Inbound and outbound travelers are required for Universal Visa System. The system aims to monitor the Visa Application System in a risk-based scenario. The real time immigration system such as the APP is integrated for the preliminary check of passengers' information. With this system, the management of the origin and destination can be prepared in advance. The monitoring of risk, such as an unauthorized person traveling across the border and the prevention of cross-border crime, can also be controlled well. At the same time, the cost of management is also decreased. 
In general, the system regarding each stage can be defined as follows:

Prearrival: Prearrival processes are mainly related to the visa system and preclearance processes. The related systems can be identified as the Electronic System for Travel Authorization (ESTA), an electronic system implemented by the Department of Homeland Security (DHS) for screening passengers before travel to the United States of America. This system is mandatory for Visa Waiver Program (VWP) travelers since January 12, 2009. The APIS refers to communications systems, electronic components, and the necessary data being collected and sent to the border control authorities before flight departure or upon arrival at the airport [21]. The APPS refers to the system of sending and exchanging passenger information in advance of international passengers. Inbound and outbound passengers changing through the terminals relate to the Customs Immigration Office, the Office of the Anti-Drug Commission and drug suppression. The National Security Council determining whether or not to allow passengers to travel by the system will reduce passenger's seal process more quickly and efficiently. The Passenger Name Record (PNR) refers to a set of data elements and standards used to guide corresponding aircraft operators to transmit the PNR to the government for information exchange in international settings, and was developed by the Passenger and Airport Data Interchange Standards, and is accredited by the International Civil Aviation Organization [21].

On Entry: The arrival process focuses on the verification of people and purpose of travel. The system relates to the entry/exit system. The entry and exit systems refer to the identification and verification of travelers. Many air borders have adopted automatic gates for the identification of the travelers in order to reduce waiting time and staff at the checkpoint. Check-in kiosks are also installed at the European borders for the identification and verification of the European travelers who travel within the union. For vehicles crossing the border, vehicle clearance system allows for people and goods declaration. The X-ray scanner and portable scanner are adopted for the identification of goods [22]. The automatic in-car clearance is now adopted in Singapore to reduce the waiting time to get-in and off the vehicle of all passengers. At the same time, the clearance of car is also verified via the X-ray scanner.

After entry: As the after-entry process focuses on tracking travelers, the in-country applications play an important role in this stage. In Thailand, according to section 38 of the 1979 Immigration Act, "House owners, heads of households, landlords or managers of hotels who accommodate foreign nationals on a temporary basis who stay in the kingdom legally, must notify 
the local immigration authorities within 24 hours from the time of arrival of the foreign national." Hence, the landlord is subject to submit the TM 30 form to the immigration office within 24 hours via many channels, such as in person at the respective office or through an authorized person at the respective office, by registered mail, or via the internet.

\subsection{Disease Control at Border Checkpoint}

The inspection of disease is an important control task at a cross-border to prevent the risk of communicable diseases from international travelers $[7,23]$. Effective and timely detection of diseases among travelers can prevent communicable disease and aid the preparation of control measures. When compared to air-travel checkpoints, it is clear that land border checkpoints put less focus on screening methods [8], and that, to be managed effectively, communicable diseases, epidemics, and pandemics need timely regional collaboration at land border-crossings also [24, 25]. The practice of screening and tracking suspected patients has already been established in air travel, with the Frankfurt model [23] that recommended screening practices for suspected air travel patients. The paper suggests prearrival, on entry, and after-entry procedures for travelers. At prearrival, the Passenger Locator Cards (PLC), a form recommended by the WHO and ICAO, is recommended for prechecking air-travelers' health condition during a pandemic [23]. Color coding to classify passengers' health condition is used after the plane has landed.

Many researchers have identified the importance of information technology adoption for disease control at border checkpoints. Noncontact infrared thermometers were used for the detection of dengue fever at Taiwanese airports between 1998 and 2007 [26]. The researcher noted that the use of thermometers for fever screening had successfully identified $45 \%$ of the infected imported cases. In general, the screening of infected travelers is done by two tools: a questionnaire and detection tools like noncontact thermal scanners for fever screening [27, 26, 28, 29]. Three health-screening strategies were used for the detection of air travelers from West African countries to Europe during the Ebola pandemic of 2006-2012 [26]. The tools for health screening included a questionnaire, trained observers, and screening devices. The first screening was done by questionnaire/observers or medical devices. In case if symptoms were detected, a second screening by medical officers was performed on suspected travelers. The timing of the screening also played an important role in disease detection since it could prevent transmission. Lucas Goal et al. have researched the entry/exit 
scenarios for infectious diseases at an air border checkpoint with three scenarios: no screening, screening at trip origins, and screening at trip destinations. The results revealed that the screening at trip origins makes a significant difference on epidemic disease control [27]. A noncontact infrared and thermal imaging cameras are recommended as the equipment to be used for detecting passengers in an epidemic [30]. In Thailand, the health officer at a point of entry has a right for screening and quarantine of a traveler in accordance with the Communicable Disease Control Act 2015 [31].

\section{Methodology}

This research aims to present a model for screening and tracking people across the border during an epidemic. The specification is focused on the integration of data and the process of organizations based on the CBM concept. Business process analysis [32] is a methodology for the identification of the As-Is and To-Be process of the border-crossing process. In the business understanding process, a review of primary and secondary data by nonparticipant observation is used for business understanding. Sources of the secondary data are the border-crossing processes with the adoption of new technology, real time health inspection, immigration, customs, and successful cases being reviewed. The primary data were collected from the nonparticipant observation at the Sadao border checkpoint, the highest ranking of border trade in Thailand. The observation focused on the bordercrossing processes on the five pillars of CBM, which consist of policy, process, people, information technology, and infrastructure and facilities with respect to the disease control. The primary data were collected from in-depth interviews with stakeholders regarding the data sharing and management of border checkpoints during the COVID-19 epidemic. The primary data and secondary data were recorded and kept as a baseline for the As-Is process $[33,34]$. The business analysis was identified and presented in the To-Be process, which combines the adoption of new technology regarding disease control. The process was demonstrated and verified by a simulation. Data sharing is an essential point of the process flow for screening and tracking of travelers $[1,4]$. The study can be divided into three parts:

\section{Part 1: Business understanding}

The five pillars of the CBM concepts are the baseline for business understanding. This step is to understand and know the baseline of the current 

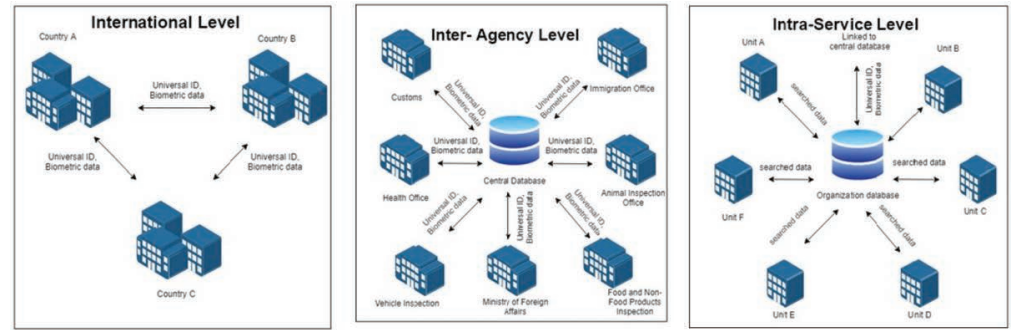

Figure 1 Level of cross-border management based on CBM concept.

situation of the cross-border management in Thailand and internationally, the need and challenges of the data, and the process of border management. The primary data of the process flow and the adoption of technology as a smart border concept as well as the convenience of travelers are observed. Literature review on the cross border management concepts, trends in technology regarding control of borders, which includes customs; immigration; and quarantine, and case studies of cross-border management during an epidemic were reviewed. In general, the objectives of the business understanding are to clarify the cross-border process in international, interagency, and intraservice levels as per the CBM concept and seek solutions for the To-Be process.

\section{Part 2: Business analysis}

The analysis of the To-Be process model was carried out as follows:

The analysis of the needs and challenges of the cross-border management: SWOT analysis was employed to determine the As-Is situation. Data collected from the nonparticipant observations and literature reviews, together with in-depth interviews with stakeholders regarding health inspection at border checkpoints, were analyzed. The results of the SWOT analysis represented the factors that are essential for the cross-border management.

The design of To-Be process model: The CBM was the concept for the redesign of the system. Mapping as the integrated border control management needs collaboration from and the integration of data and process with agencies related to border control. The redesign of the cross-border process for disease control was divided into three stages: prearrival, on arrival, and after entry. The control of disease at cross-border checkpoints was put as the first priority for protecting both the country's public health system and the security of the country $[8,24]$. The Frankfurt model was adopted for the detection of suspect travelers [23]. The selection of technology in the 


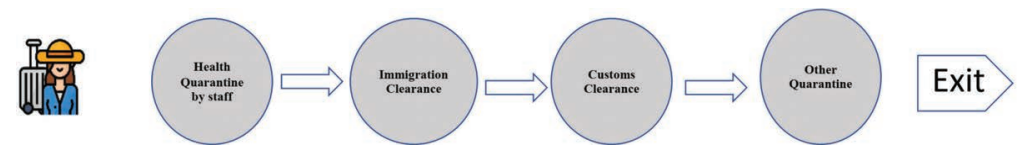

Figure 2 The border checkpoint process before the COVID-19 epidemic.

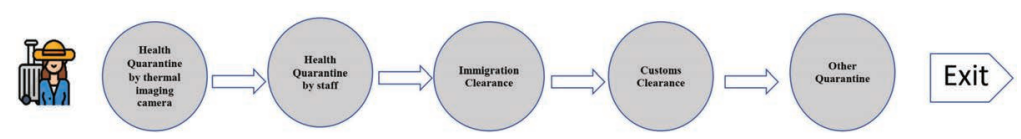

Figure 3 The border checkpoint process during the COVID-19 epidemic.

system was based on the noncontact surface concept [35] together with the performance of unique identification $[36,37]$ in order to protect staff as well as the travelers from the transmission of disease. Walkthrough metal door detection with the combination of fever screening and immigration clearance is a choice of the equipment for the screening of the traveler at the entry process. This equipment is verified and tested for its suitability in many cases [38].

\section{Part 3: Verify the model by simulation}

Simulation is a method to verify and provide proof of the control at a border checkpoint [39]. Simulation modeling is required for the verification of the conceptual model. Transmission of the disease is also an important point for the design since the length of stay in any place affects the possibility of an infection. In order to prevent and control the epidemic, the As-Is situation before the COVID-19 epidemic has set up a health quarantine by health staff at the first station, followed by an immigration control check, and customs clearance, respectively.

During the COVID-19 epidemic, the checkpoint agencies have set up one more station for the health quarantine by setting up a thermal imaging camera at the first station, followed by the second health check by the health staff, and then immigration control check, and customs clearance. The processing time at the border checkpoint of the traveler was also increasing due to the operation of disease control for health protection.

The design of the To-Be process is the reference to the conceptual model, and the selection of technology is based on the decreasing time of operation and in accordance with the task of cross-border activities. Walkthrough fever screening metal door detection is selected for the health quarantine, immigration control, and customs clearance with data sharing and real-time base. 


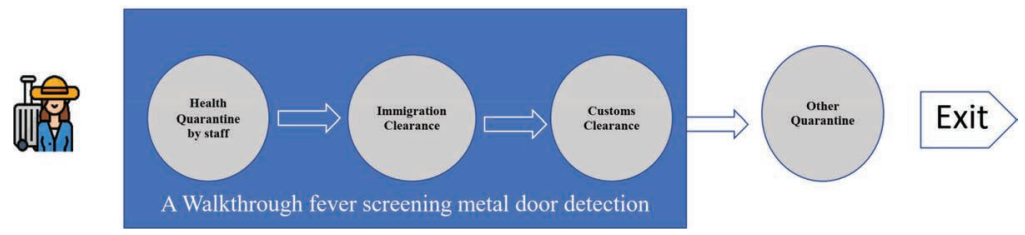

Figure 4 To-Be process.

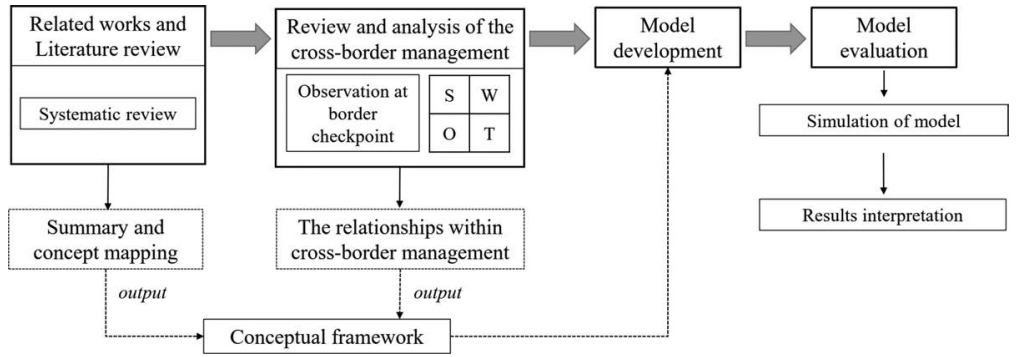

Figure 5 Conceptual framework.

The simulation will demonstrate the total time for the border-crossing process during disease control. The simulation uses an input number of 1,200 travelers per hour in a Poisson distribution, reference from the peak hour of Sadao Border Checkpoint. Based on the ICAO standards, the immigration process should not exceed 45 seconds. The total time with all inspections at the border checkpoint before the COVID-19 epidemic is 15 minutes.

Overall, the methodology of the research is shown in Figure 5.

\section{Results}

\subsection{Review of Literature and Observation at the Border Checkpoint}

The results of review of cross-border process and observation at border checkpoint in Thailand are analyzed. SWOT is a tool for grouping the data. Details are shown in Figure 6.

As a result, the weakness and threat of the cross-border management in Thailand are information sharing [40] and cross-border harm and disease from travelers. To design the model of the cross-border management for disease control, information sharing is mandatory. 


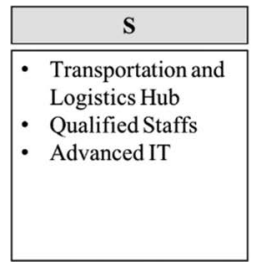

\begin{tabular}{|ll|}
\hline \multicolumn{1}{|c|}{ W } \\
\hline \hline - Non - Real Time \\
Data Sharing for \\
Cross Border \\
- Lack of \\
Infrastructure \\
Sharing \\
\hline
\end{tabular}

\begin{tabular}{|ll|}
\hline \multicolumn{1}{|c|}{ O } \\
\hline \hline - & Policy Support \\
- International & Standard \\
Accreditation and \\
Compliance
\end{tabular}

\begin{tabular}{|ll|}
\hline \multicolumn{1}{|c|}{ T } \\
\hline \hline - & Cross Border \\
Security \\
- Transnational \\
Crime \\
- International Spread \\
of Disease \\
- Disease Outbreak \\
\hline
\end{tabular}

Figure 6 SWOT analysis of cross-border management.

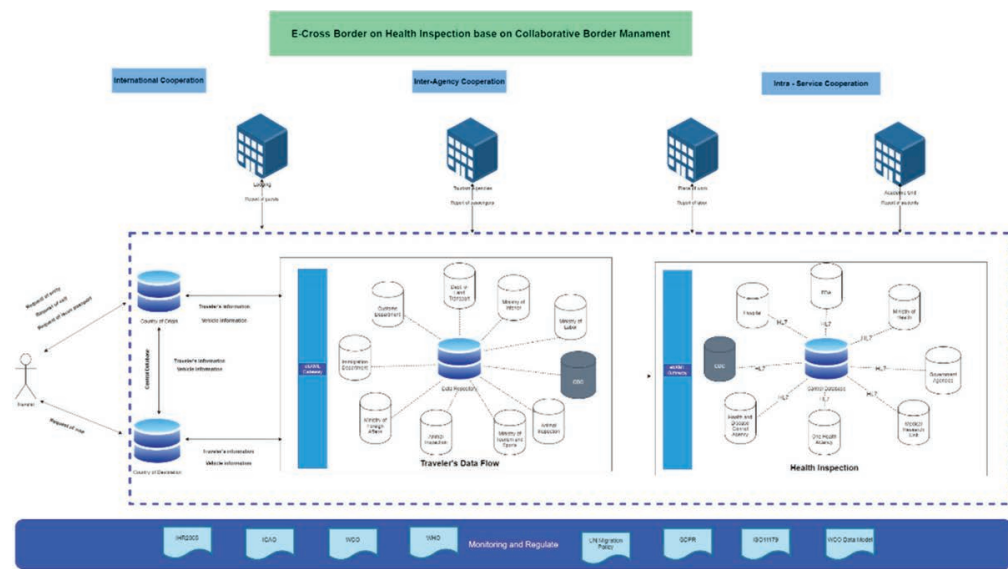

Figure 7 Conceptual of E-crossing border on disease control base on collaborative border management.

\subsection{Design of the New Process}

According to the CBM concept, the redesign of the process of disease control can be seen in Figure 7.

Figure 7 indicates the process of the smart border for disease control. The activities can be separated into three levels based on the CBM concept. Information sharing and the use of advanced information technology are the main keys to the model. The concepts of the APIS and APPS are adopted for the screening of travelers in terms of protecting and controlling security, disease, and other cross-border threats [34].

The border-management process can be divided into three stages: preentry, on arrival, and after entry. However, in this paper, activities related to the border crossing can separated into four areas: request of e-passport, request of vehicle entry, request of e-VISA, and request for entry and completing the Traveler Locator Form. The actors in these activities are the 
travelers and stakeholders. However, all these activities need collaboration on both physical and virtual borders for a smooth and timely process and flow of information. At the international level, once the traveler applies for each activity, the data will firstly be linked to the database of the country of origin and then identification will be checked and verified. The data repository is a temporary installation of essential data, including passport ID, biometric data, and history of crossing the border [20]. In case of disease control, the last visit of a traveler within 3 months will be the focus. The set of common data for linkage among organizations at the interagency level is set for a shared and real-time link [41]. To prevent and control the disease, the DDC will update the case of disease control and lists among health organizations within the country in the intra-agency level via HL7, the health data exchange standard. Stakeholders in the tourism and logistics business also play an important role in preventing and controlling the disease. These stakeholders representing lodging personnel, tourism agencies providing inter transportation and tours, and academic institutes where travelers hold student visas, are responsible for reporting traveler information in which part of their contribution is to the web provider. The benefit of the report is for the allocation of service of infrastructure and facilities, staff, and other necessities at the checkpoint and the tracking of travelers while in the country. Currently, after the outbreak of the Coronavirus, the tracking of travelers is done by unlinked data from each organization, which may take time and result in data duplication. However, in this model, tracking is performed by checking through the repository database with the common standard-setting. Biometric data and traveler passport ID are the keys for real-time links, and the visualization of data by intelligent process automation will help track and report a case of disease [42]. Moreover, the stakeholders also benefit from the safety and the preparation of their services in cases of suspected travelers being found. Lastly, to ensure compliance, policy and cross-border standards are used to monitor the regulatory supports. Those policies and standards consist of the WTO and WCO for securing the supply and logistics of goods and personnel [3], UN migration policy for the monitoring and controlling of migration of people in each criterion, and International Health Regulations (IHR2005) for outbreak and disease control. General Data Protection and Regulations (GDPR) is the standard for securing and protecting data privacy in the cross-border transaction $[43,44,45]$. To ensure the smooth and secured use of information technology, software, and peripherals, the ISO standard is selected for compliance. 
More specifications of the process can be defined as follows:

\subsubsection{At pre-entry stage}

There are three activities operating at this stage, namely the request for passport, request for visa, and request for vehicle entry. Details are as follows:

\section{Activity 1: Request for passport}

At the international level, the traveler is responsible for the application of his or her passport in his or her original country. At a smart border, the passport is a must for e-passport, which includes a biometric data record. The chip will identify the passport owner through three types of biometric data, namely fingerprint, iris, and facial image. Once the application for an e-passport is made, the biometric data of the passport owner is recorded. At the interagency level, the responsible organization, in this case a consul or embassy, will record the use of the passport and biometric data and the set of data will be shared with the central database at the interagency level. These data are the passport ID, national ID, and biometric data, which are a common set of traveler data for linkage with other organizations. In case of outbreak control, the DDC can check and track the border-crossing history of the traveler by searching for the passport ID and biometric data in the central database. At this stage, the use of information technology and infrastructure, including a web portal and biometric scanner, are essential for the accuracy and timeliness of the data and flow of the process.

\section{Activity 2: Apply for e-VISA}

When a traveler needs to travel to a country which has no guaranteed immigration policy, a VISA is needed. A smart border system requires an e-VISA for the smooth and timely flow of travelers [43]. At this stage, at the international level, a traveler is subject to apply for an e-VISA at the web portal of the destination country based on the immigration policy. Once the application is done, the destination country will then check the applicant's personal information and the history of border-crossing. Necessary database is searched for the applicant's biometric data and personal information and linked for verification of national safety on migration. To control the outbreak, the last visit to the country or the applicant's visits to other countries will be checked before prior checking of the outbreak. If the applicant's history is found suspect, the destination country may deny the issue of an e-VISA for that applicant. However, the success or denial of the e-VISA application depends on the severity level of the outbreak based on the WHO standards and the national law. The results of the application will be delivered 
to the applicant directly via the web portal. At the same time, the results of the application will also be linked to the data repository of the two countries.

At the pre-entry stage, in case of travel via international public transportation such as international bus or train, travel agencies are responsible for sending passenger information, including passport ID, first name, and last name to the Advance Passenger Registration System at least 1 hour before departure. Likewise, in case of travel via private vehicle, travelers are responsible for submitting their information together with all passenger information and vehicle information to the Advance Vehicle Registration System at least 1 hour before departure. The benefit of this registration process is that it helps estimate vehicles and travelers at the border checkpoint at any given period, allowing for prior space and operation management at the checkpoint. For outbreak control, once the list is uploaded, searching for passport ID in the repository database at the international level is the start, and then the boarding history of travelers is identified. If the history of one traveler appears at highrisk of outbreak of the DDC record, the prepreparation for outbreak control at the border checkpoint is notified. The responsible staff of the country of origin and destination may prepare special checking and special equipment if needed. However, if the list is found normal, the benefit of this service is for the allocation of the management of the border checkpoint as previously mentioned.

\subsubsection{On arrival}

\section{Activity 3: On arrival}

Once the traveler enters the cross-border checkpoint, he or she will walk by the fever screening metal door detection and immigration clearance. The dynamic detection [43] is a technique for the identification and verification of the traveler and travel documents. For the health detection, the capacity of detection should not exceed 8 people in a row [44]. The health check, immigration check, and customs check will be carried out. If there is nothing to be suspected, the traveler is ready for entry. However, if the traveler has been noted of traveling in the risk countries of the DDC announcement, he/ she is needed to have a secondary health check by the health staff once again.

In case of the traveler's temperature exceeds $38^{\circ} \mathrm{C}$, the secondary check of health conditions is required. The health inspection is the first process they need to go through. The hand-held thermography camera is required

for checking the health conditions of the travelers. The infrared imaging cameras are used in order to capture the in-normal sign of temperature. The 
concept of using nonintrusive equipment for the human health inspection of both staff and officer is well known. Based on the ISO/TR 13154:2017 medical electrical equipment standard a screening thermograph complying with the IEC 80601-2-59 [46] is a noncontact, accurate, and repeatable means of quickly screening individuals for fever when proper procedures are followed [47]. If the infrared temperature screening is normal, then the traveler is able to move to his or her next step in the immigration process. The immigration process is the next step. A traveler is required to use an automated gate in a queue. The biometric technology is adopted to prevent identity fraud [43]. The immigration stage via automated gate starts with the verification of an e-Passport. The traveler first opens the e-Passport to the biographic and picture page and places it face-down on the reader so that it can scan the picture and read the key information. Next, the traveler must look straight at the camera in the front for facial image capture. These steps are for the identification of the traveler, visa check, criminal check, and visa overstay check. The traveler is required to stand still until the green light is flashed, and can then remove the passport and exit the gate.

During the process, intelligent process automation, risk assessment, and risk profile will be sorted for risk identification of the traveler. Moreover, video analytics is enabled for the motion capturing of the traveler. A document examination system, linked to international databases, is ready for the verification of supporting documents, such as visa and related documents.

The final step is the identification of belongings. Radiation control system is for bearer checking process. The travelers must put their luggage to the plate and bring it to check via the scanner. The type of scanner recommended is a 3D scanner, which is more effective at searching things inside solid surfaces. The specification of the X-ray scanner is based on the World Customs Organization Guidelines [48].

During all these processes, the data are sent to the repository ready to be searched for and retrieved. In case of an outbreak control, once the traveler is found infected or suspected of disease, the tour agency will be informed of the infection and immediately guided on how to manage the case in a sanitary manner via the web portal. This is for the disease control at the international level.

\subsubsection{After entry}

Once a traveler arrives at his or her place of stay, the residence's owner is required to update their guest's information with the Immigration Bureau. Currently, the data from resident is kept at the Immigration Bureau and will 
be provided to other organizations on request. The data set of the process will be directly stored in the data repository of the border agencies at the interagency level. This is crucial in case of tracking travelers in various cases. In case of disease control, this is for sending updated information of disease control to the resident for good preparedness. As for the border agencies, the current location of travelers can be retrieved for tracking at any time. However, the right and privacy of the traveler's personal data is protected by legal regulation and national law.

\subsubsection{The concept of data sharing for smoothness and timeliness of the flow}

Based on the activities as summarized in Sections 4.2.1-4.2.3, data will be transferred smoothly and promptly. To clarify, two main data are divided in the data layer: traveler data and vehicular data. Data sets for the traveler are passport ID, national ID, biometric data, and personal info. These data will be recorded from the preregistration of the traveler at the pre-entry stage. The data sets in this stage are linked at the international level among the original country and the destination country. During the biometric identification and verification, data is also linked at the international level using passport ID. Health data will be recorded in the health checking process. Place of stay will be recorded in the after-entry process. The data sets will be linked to three main border management levels, which are international level, interagency level, and intraservice level.

\subsection{Model Verification}

Simulation of the entry process is used for the verification of the model. The experiment dataset has been randomly generated from a simulation system based on an in-depth interview output and reference from Sathaporn Opasanon and Songyot Kitthamkesorn [49]. Matlab software is used as a simulation program. The specifications of the infrastructure and information technology are based on section 4.2. The standard time of the inspection is considered to be effective in terms of decreasing time of the process. Data requirement of the simulation is provided in Table 1.

The As-Is process and number of immigration booths, and customs clearance are referenced from the current system at the Sadao border checkpoint. The As-Is process is shown in Figure 3.

Currently, at the border checkpoint of Thailand, the steps of traveler clearance were started from the immigration clearance, the health quarantine, 
Table 1 Data requirements for the simulation

\begin{tabular}{|c|c|}
\hline Process & Data requirements \\
\hline $\begin{array}{l}\text { The base case of the } \\
\text { simulation }\end{array}$ & $\begin{array}{l}\text { - Two traveler types are employed: preregistra- } \\
\text { tion and no registration } \\
\text { - Traveler arrivals in Poisson distribution with an } \\
\text { interarrival time of } 3.16 \\
\text { - The model estimated that the maximum num- } \\
\text { ber of traveler arrives at a border checkpoint is } \\
1,200 \text { traveler per hour. } \\
\text { - The criteria of health quarantine is in accor- } \\
\text { dance with the WHO standard [50]. } \\
\text { - Queue service discipline: First-Come-First- } \\
\text { Serve }\end{array}$ \\
\hline $\begin{array}{l}\text { As-Is Process } \\
\text { Border clearance } \\
\text { 1. Health quarantine by } \\
\text { staff } \\
\text { 2. Immigration clearance } \\
\text { 3. Customs clearance }\end{array}$ & $\begin{array}{l}\text { - Distribution of service time of each station } \\
\text { - A thermal scanner with the detection of } 8 \\
\text { travelers/min } \\
\text { - Health quarantine by staff is in the range of } 1-2 \\
\text { min } \\
\text { - Immigration clearance based on the ICAO } \\
\text { standard is no later than } 45 \text { seconds } \\
\text { - Customs clearance is } 1 \mathrm{~min}\end{array}$ \\
\hline To-Be process & $\begin{array}{l}\text { - Walkthrough metal detector with the capacity of } \\
\text { detection of } 8 \text { travelers in a row with process time } \\
\text { of } 2 \text { seconds [51]. }\end{array}$ \\
\hline
\end{tabular}

and the customs clearance. Before the COVID-19 epidemic, the infrastructure at the Sadao border checkpoint consisted of 8 immigration booths with 2 customs X-ray scanners for customs clearance. During the COVID-19 epidemic, the thermal imaging camera has been settling up in the first process for fever screening, followed by health quarantine by health staff, immigration clearance, and customs clearance. However, as mentioned in the previous section, there is still no data linkage among organizations. In case of tracking a suspected traveler, the organizations need to ask for the permission of sending related information to the stakeholders. Based on Figure 7, the ToBe process will combine the check of immigration (I), health quarantine (Q), and customs clearance within the same process as walkthrough CIQ. The use of a metal detector with the combination of thermal imaging cameras and sensors will automatically detect both the identity fraud of the traveler, their belongings as well as the health conditions of the traveler simultaneously. This is also beneficial in the prevention of the health staff for direct contact with the suspected, infected traveler for health identification. 
The To-Be process is mentioned in Figure 4.

The simulation is a test based on the As-Is and To-Be process of the inspection at a border checkpoint with three purposes:

(1) Comparison of the nonsuspect traveler among the current system (1 thermal imaging camera, 8 health quarantine staff booths, 8 immigration booths, and 2 customs clearance booths) and the To-Be system.

(2) Comparison of detection time on the suspected infected traveler of the As-Is and To-Be process.

(3) Comparison of the average process time of the system of the As-Is process with two sets of the As-Is process ( 1 thermal imaging camera, 8 health quarantine staff booths, 8 immigration booths, and 2 customs clearance booths) with the To-Be process (a fever screening metal door detector and immigration clearance check).

\section{Results}

\section{Comparison of the nonsuspect traveler of As-Is process and To-Be process}

The simulation results show that the To-Be process with the setup of walkthrough fever screening metal detection can be identified and verified of both identifying and verifying health conditions of a traveler faster than the current process. Base on data randomly generated from the simulation system, in 1 hour with 1,124 travelers with 722 nonsuspect travelers, the identification of the traveler by walkthrough metal detector takes 1.108 seconds while the whole process of the As-Is system in 8 booths took 19 minutes. The process time of the As-Is system is a bit higher than the process time before the COVID-19 epidemic due to the additional of the second check of health quarantine. Meanwhile, the list of an infected traveler with the ID and time at the border checkpoint is sent to the related organizations for the purpose of notifying. It is obvious that the To-Be process is capable to identify all travelers within the limited time.

\section{Detection time of a suspected infected traveler}

One factor related to the spread of the epidemic is the length of stay in one place since spending more time in one place increases the possibility of infection. This scenario focuses on the detection time of a suspected infected traveler. The criterion of detection is to detect those who have temperature in excess of $38^{\circ} \mathrm{C}$.

The detection of a suspected infected traveler is based on the recommendations of WHO criteria. Those who have a temperature above $38^{\circ} \mathrm{C}$ is 


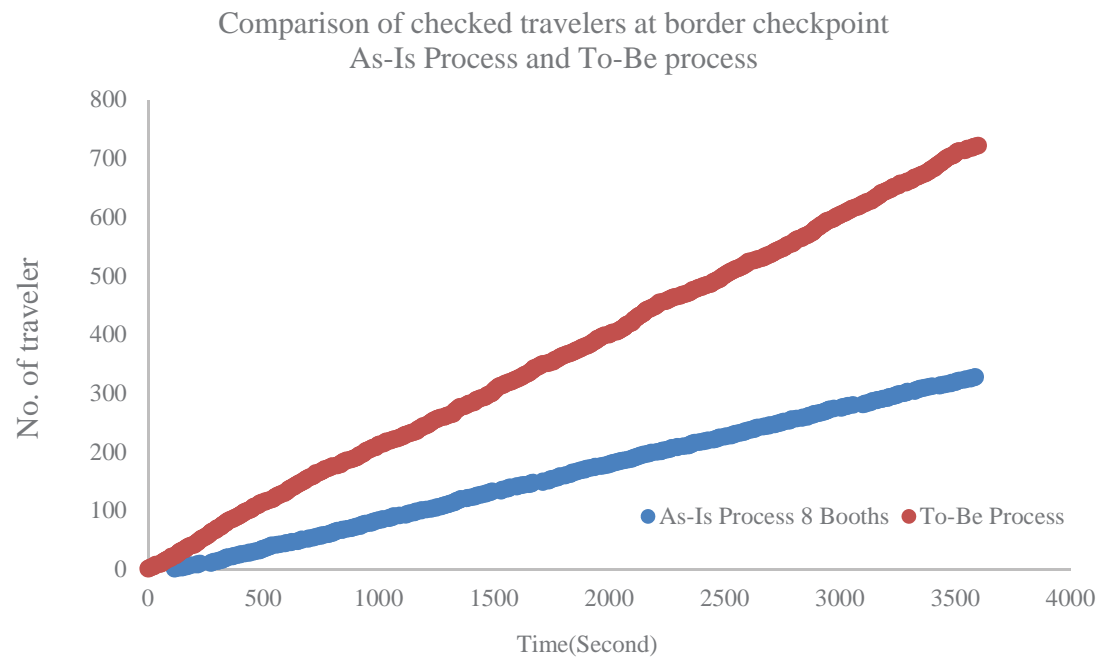

Figure 8 Comparison of success screen traveler of To-Be and As-Is Process.

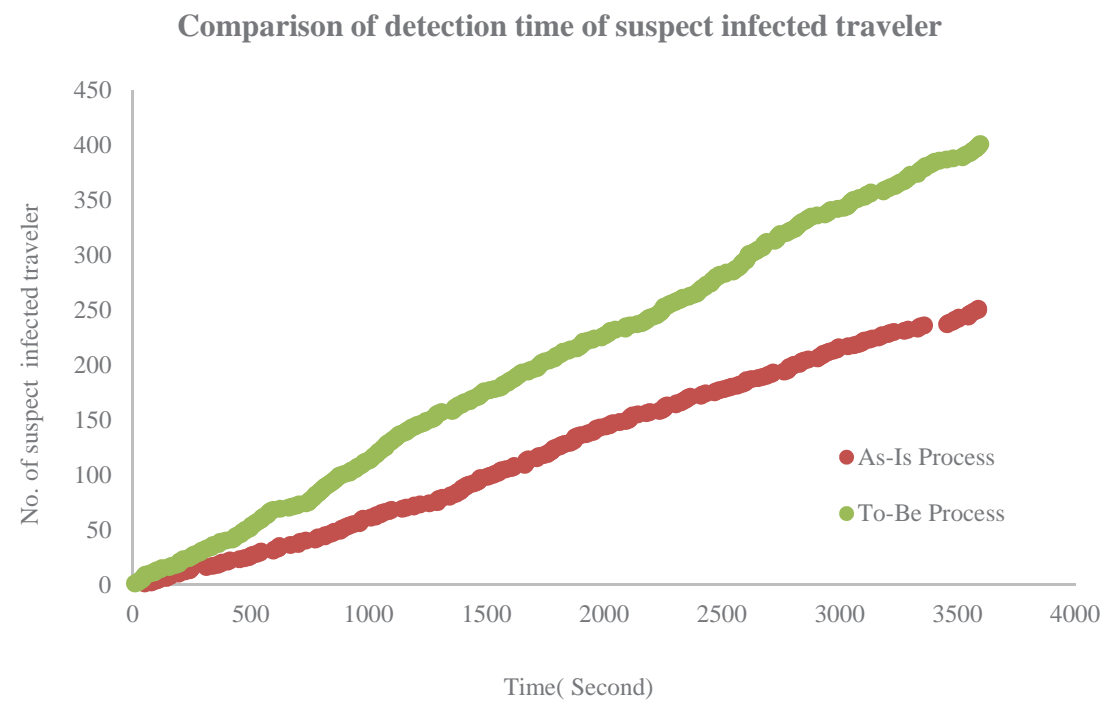

Figure 9 Comparison of detection time of suspect infected traveler.

suspected of infection. The researcher has simulated in the worst-case scenario, 402 travelers are declared suspected of infected. As stated in Figure 9, within 1 hour of 402 suspected travelers, the To-Be process is capable of detecting 2 times faster than the As-Is process. With the distribution of 


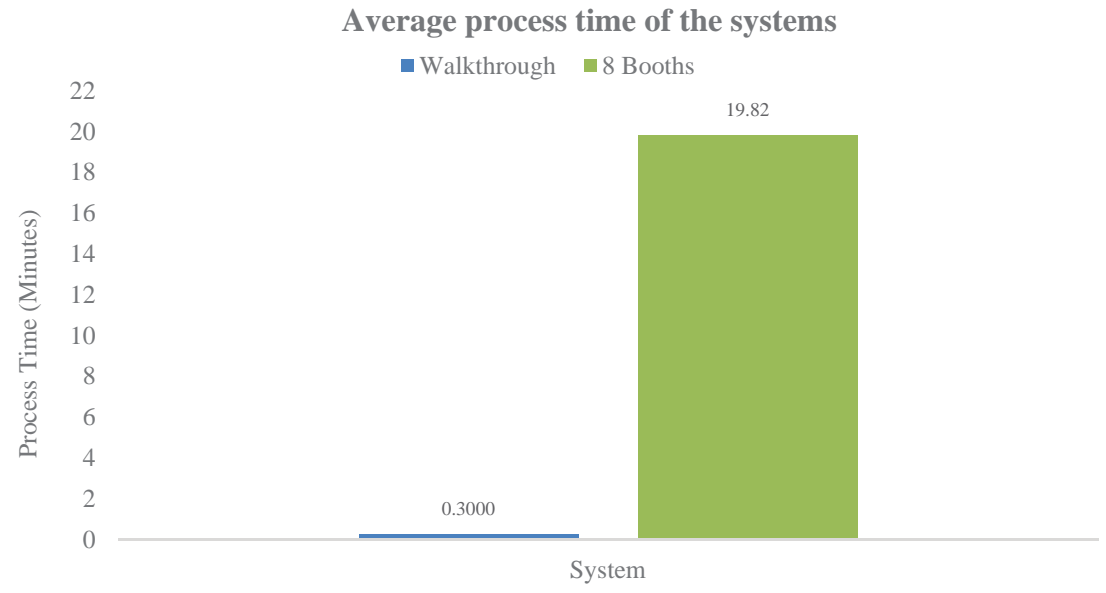

Figure 10 Average process time of the system.

travelers, the same person will be detected by the To-Be system within the 1.108 seconds when the traveler passes through the walkthrough gate. As the data is in time series, and if there is any delay in the queue for the amount of time, then the unconnected traveler would be displayed in Figure 9 during the 3200 to 3400 seconds of the As-Is process.

\section{The average process time of the system}

The average process time of the system is calculated with the sum of the average theory. Figure 10 demonstrated that the To-Be process with the setup of the walkthrough fever screening metal detection took less time for identification and verification of health conditions of the travelers than the current process. In 1 hour with 1,124 travelers with 722 nonsuspect travelers, the identification of the traveler by the walkthrough takes 0.3 seconds while the whole process of the As-Is system in 8 booths took 19 minutes. With this result, the To-Be process can replace the number of staff who are working at the booths with at least half of the current system.

\section{Discussion and Findings}

The conceptual model of e-cross border management consists of the crossborder activities in prearrival, entry, and after entry processes. The design is based on the CBM concept for increasing the concept of data sharing and linkage among the related organizations at an international level, interagency 
level, and intraservice level. This paper has suggested the model of the ecross border with the use of technology and the redesign of the border checkpoint based on the conceptual model concept. For disease control, sharing of data plays an important role in protecting and controlling disease via tracking of travelers. Walkthrough fever screening metal detection is recommended to support disease control and in the concept of e-border. The benefits of the selected technology include shortening the processing time of health quarantine, immigration process, and customs clearance. Moreover, it is to support the use of a noncontact infrared camera which will protect health staff and others from contact with the disease carrier. Based on the results of the simulation, we observe that the processing time of the entry of the traveler with walkthrough fever screening metal door detection can save the processing time of each traveler by 14 minutes than the current one. Moreover, according to the real-time and data-linkage concept of the model, once the traveler has completed the identification and verification of all processes, his or her data will be stored at the central database and be able to be retrieved by related organizations as per request. In the case of the preregistration of the traveler, the details are beneficial for the related agencies for prearrangement and resource allocation. With this model, once the traveler has been confirmed of infection, the related agencies can be notified as necessary under the legal regulations.

\section{Conclusion}

Security and safety of a nation are the common goals of the economy of the nation. Border checkpoint plays a critical role for the security and safety of the nation. The tasks of the border checkpoint consist of human health inspection, customs, immigration, sanitation of plants, and animal health. The concept of e-border showed that it is able to increase the efficiency of cross-border management via the linkage of the data with other information support. With this conceptual model and the proof by simulation, the concept of the e-border model is worth implementation. This model shows that the conceptual model can be effectively used to track the traveler before and during entry into Thailand. In case of any emergency, border agencies are able to track data from the data repository in real time. The adoption of advanced technologies for disease control, such as walkthrough fever screening metal door detection; an infrared imaging scanner; fixed and portable devices; and together with the AI with advanced equipment, will increase the confidence of crossing the Thailand border for both travelers and staff working at the border 
checkpoint. The operating cost at the border checkpoint also decreases with decrease in staff and the processing time of the traveler at a border checkpoint. Moreover, the conceptual model is aligned with the policy related to border control management.

\section{Acknowledgment}

The authors would like to thank the Office of the Permanent Secretary, Ministry of Higher Education, Science, Research and Innovation, Thailand for the support. This research has been approved by the Research Committee on ethics of the Institutional Review Board of Mahidol University in the No.CIRB 2019/265.0710.

\section{References}

[1] P. Boriboonrat, "Collaborative Border Management in Thailand and Neighboring Countries: Needs , Challenges and Issues," International of Criminal Justice Sciences, vol. 8, no. 1, pp. 1-12, 2013.

[2] S. R. Jain, "Coordinated border management: the experience of Asia and the Pacific region 1," vol. 6, no. 1, pp. 63-76.

[3] The World Bank, Border Management Modernization. 2011.

[4] United Nations for Economic and Social Commission for Asia and the Pacific (ESCAP), "Improving Border Management to Facilitate Trade in SPECA: Challenges and Prospects," vol. ST/ESCAP/, pp. 1-63, 2010.

[5] A. Kmonpetch, "The Phenomenon of Cross-Border Human Trafficking: Complexities of Exploitation Issues in Thailand," Kyoto Working Papers on Area Studies: G-COE Series, no. 104, pp. 1-21, 2011.

[6] Y. C. Lee, "Human Trafficking Across Borders and the need for A Global Response," 2014.

[7] Center for Disease Control and Prevention, "Public Health Surveillance Using Emergency Medical Service Logs -U.S. -Mexico Land Border, El Paso, Texas, 2009.” pp. 649-653, 2010.

[8] S. H. Waterman, M. Escobedo, T. Wilson, P. J. Edelson, J. W. Bethel, and D. B. Fishbein, "A new paradigm for quarantine and public health activities at land borders: Opportunities and challenges," Public Health Reports, vol. 124, no. 2, pp. 203-211, 2009.

[9] B. McCloskey, O. Dar, A. Zumla, and D. L. Heymann, "Emerging infectious diseases and pandemic potential: Status quo and reducing 
risk of global spread," The Lancet Infectious Diseases, vol. 14, no. 10, pp. 1001-1010, 2014.

[10] R. Sakano, K. Obeng, and K. Fuller, "Airport security and screening satisfaction: A case study of U.S.," Journal of Air Transport Management, vol. 55, pp. 129-138, 2016.

[11] ICAO, ICAO TRIP Guide on Border Control Management. 2018.

[12] EU-LISA, "Smart Borders Pilot Project: Report on the technical conclusions of the Pilot," 2015.

[13] P. Boriboonrat, "Collaborative Border Management in Thailand and Neighboring Countries: Needs, Challenges and Issues," International Journal of Criminal Justice Sciences, vol. 8, no. 1, p. 1, 2013.

[14] International Organizations for Migration (IOM), "Foundation Training Officers, Law Enforcement Smuggling, Combating Smuggling of Migrants and Trafficking in Persons." 2018.

[15] European Commission, "Guidelines for Integrated Border Management in EC External Cooperation," 2010.

[16] Border Scetor Governance Group, "Border Sector Strategy: 2008-2013 A Framework for Collaboration for Border Sector Agencies," 2013.

[17] World Customs Organization, "Coordinated Border Management Compendium." 2006.

[18] T. Doyle, "Collaborative border management," World Customs Journal, vol. 4, no. 1, pp. 15-22, 2010.

[19] P. Lehtonen and P. Aalto, "Smart and secure borders through automated border control systems in the EU? The views of political stakeholders in the Member States," European Security, vol. 26, no. 2, pp. 207-225, 2017.

[20] European Commission, "Proposal for a REGULATION OF THE EUROPEAN PARLIAMENT AND OF THE COUNCIL amending Regulation (EU) 2016/399 as regards the use of the Entry/Exit System." 2016.

[21] J. Vine, “'Exporting the border'? An inspection of e-Borders,” 2013.

[22] United Nations for Economic and Social Commission for Asia and the Pacific(ESCAP), "Model on integrated controls at border crossings," 2012.

[23] W. Gaber, U. Goetsch, R. Diel, H. W. Doerr, and R. Gottschalk, "Screening for infectious diseases at international airports: The Frankfurt model," Aviation Space and Environmental Medicine, vol. 80, no. 7, pp. 595-600, 2009. 
[24] R. D. Merrill et al., "Responding to communicable diseases in internationally mobile populations at points of entry and along porous borders, Nigeria, Benin, and Togo," Emerging Infectious Diseases, vol. 23, no. December, pp. S114-S120, 2017.

[25] World Health Organization (WHO), "Operational Guidelines on CrossBorder Control of Priority Communicable Diseases," no. November. 2001.

[26] M. M. Kuan, T. Lin, J. H. Chuang, and H. S. Wu, "Epidemiological trends and the effect of airport fever screening on prevention of domestic dengue fever outbreaks in Taiwan, 1998-2007," International Journal of Infectious Diseases, vol. 14, no. 8, pp. e693-e697, 2010.

[27] L. Gold, E. Balal, T. Horak, R. L. Cheu, T. Mehmetoglu, and O. Gurbuz, "Health screening strategies for international air travelers during an epidemic or pandemic," Journal of Air Transport Management, vol. 75, no. November 2018, pp. 27-38, 2019.

[28] P. Ghassemi, T. Joshua Pfefer, J. P. Casamento, R. Simpson, and Q. Wang, "Best practices for standardized performance testing of infrared thermographs intended for fever screening," PLoS ONE, vol. 13, no. 9, pp. 1-24, 2018.

[29] K. Wickramage, "Airport Entry and Exit Screening during the Ebola Virus Disease Outbreak in Sierra Leone, 2014 to 2016," BioMed Research International, vol. 2019, 2019.

[30] European Centre for Disease Prevention and Control, "Infection prevention and control measures for Ebola virus disease Entry and exit screening measures," European Centre for Disease Prevention and Control, no. October, pp. 2-9, 2014.

[31] Department of Disease Control, "The Communicable Disease Control Regulations," 2003. [Online]. Available: https://ddc.moph.go.th/viral pneumonia/eng/file/laws/laws_eng_01_030263.pdf. (Accessed 3 February 2020)

[32] United Nations for Economic and Social Commission for Asia and the Pacific(ESCAP), Business Process Analysis, no. September. 2012.

[33] G. Rodirigues, "Measuring Border Agency Performance: Options for Benchmarking."

[34] European Commission, "Technical Study on Smart Borders," 2014.

[35] J. A. Jacobs and M. Van Ranst, "Biometric Fingerprinting for Visa Application: Device and Procedure Are Risk Factors for Infection Transmission,” vol. 15, no. 5, pp. 335-343, 2008. 
[36] N. Anne et al., "Feasibility and acceptability of an iris biometric system for unique patient identification in routine HIV services in Kenya," International Journal of Medical Informatics, vol. 133, no. October 2019, 2020.

[37] P. Pointner, "Hybrid tech: the future of biometric ID verification?," Biometric Technology Today, vol. 2017, no. 8, pp. 8-10, 2017.

[38] J. Guag, B. Addissie, and D. Witters, "Personal medical electronic devices and walk-through metal detector security systems: Assessing electromagnetic interference effects," BioMedical Engineering Online, vol. 16, no. 1, pp. 1-15, 2017.

[39] A. Hoffman and E. Bhero, "A Simulation Approach to the Optimized Design of Cross-border Operations," IEEE Conference on Intelligent Transportation Systems, Proceedings, ITSC, vol. 2015-Octob, pp. 14161423, 2015.

[40] C. Standing Committee for Economic and Commercial Cooperation of the Organization of Islamic Cooperation, "Improving the Border Agency Cooperation Among the OIC Member States for Facilitating Trade," 2016.

[41] M. Nalin et al., "The European cross-border health data exchange roadmap: Case study in the Italian setting," Journal of Biomedical Informatics, vol. 94, no. November 2018, p. 103183, 2019.

[42] Accenture, "Emerging Technologies at the Border," 2017.

[43] Y. Liu, "Scenario study of biometric systems at borders," Computer Law and Security Review, vol. 27, no. 1, pp. 36-44, 2011.

[44] S. Shams, "GDPR and immigration requirements: how to fulfil both," Employment Law Journal, vol. July/ Augu, no. August, 2018.

[45] GSMA, "Regional Privacy Frameworks and Cross-Border Data Flows How ASEAN and APEC can Protect Data and Drive Innovation," 2018.

[46] ISO, "ISO/TR 13154:2017(en) Medical electrical equipment- Deployment, implementation and operational guidelines for identifying febrile humans using a screening thermograph." [Online]. Available: https:// www.iso.org/obp/ui/\#iso:std:iso:tr:13154:ed-2:v1:en:fn:1. (Accessed 10 February 2020)

[47] P. Hausfater, Y. Zhao, S. Defrenne, P. Bonnet, and B. Riou, "Cutaneous infrared thermometry for detecting febrile patients," Emerging Infectious Diseases, vol. 14, no. 8, pp. 1255-1258, 2008.

[48] World Customs Organization, "Report on Guidlines for the Procurement and Deployment of Scanning /NII Equipment," 2018. 
[49] S. Opasanon and S. Kitthamkesorn, "Border crossing design in light of the ASEAN Economic Community: Simulation based approach," Transport Policy, vol. 48, pp. 1-12, 2016.

[50] World Health Organization (WHO), "Key considerations for repatriation and quarantine of travellers in relation to the outbreak of novel coronavirus 2019-nCoVle." [Online]. Available: https://www.who.in t/news-room/articles-detail/key-considerations-for-repatriation-and-qu arantine-of-travellers-in-relation-to-the-outbreak-of-novel-coronaviru s-2019-ncov. (Accessed 17 February 2020).

[51] N. G. Paulter, "The National Institute of Justice Standards for HandHeld and Walk-Through Metal Detectors Used in Concealed Weapon and Contraband Detection," no. June, 2002.

\section{Biographies}

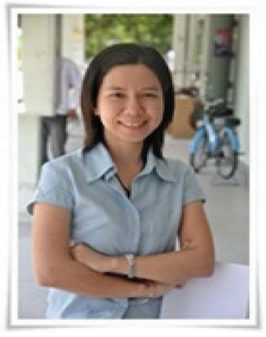

Pakamas Pairot received her B.Sc. degree in business management (business computer) from the Prince of Songkla University, Thailand in 2002. She also received her M.Sc. degree in information technology management from the Prince of Songkla University in 2010. She has experience in database management and business analytics. She is currently a Ph.D. student in IT management, Mahidol University. Her areas of research interests are data mining, big data, and business management. 


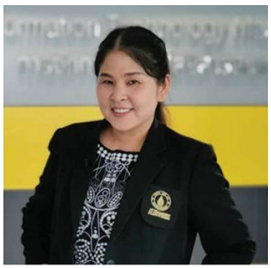

Supaporn Kiattisin received her B.Eng. degree in applied computer engineering from the Chiang Mai University, Chiang Mai, Thailand, in 1995. She also received her M.Eng. degree in electrical engineering and the Ph.D. degree in electrical and computer engineering from the King Mongkut's University of Technology Thonburi, Bangkok, Thailand, in 1998 and 2006, respectively. She is currently the program director of Technology of Information System Management Division, Faculty of Engineering, Mahidol University, Thailand. Her research interests include computer vision, image processing, robot vision, signal processing, pattern recognition, artificial intelligence, IoT, IT management, digital technologies, big data, and enterprise architecture with TOGAF 9 certification. She is a member of the IEICE and TESA. She served as a Head of the IEEE Thailand Chapter in Biomedical Engineering. She also served as the Chairman of the TimesSOC Transaction Thailand. She has expertise in Enterprise enterprise Architecture architecture (EA), data sciences, and information technology in E-government and digital economy (DE). 
